\title{
NIIIII Language Barriers, Physician-Patient Language Concordance, and Glycemic Control Among Insured Latinos with Diabetes: The Diabetes Study of Northern California (DISTANCE)
}

\author{
Alicia Fernandez, MD ${ }^{1,6}$, Dean Schillinger, $M D^{2,3}$, E. Margaret Warton, $M P H^{4}$, Nancy Adler, $P h D^{5}$, \\ Howard H. Moffet, MPH', Yael Schenker, MD', M. Victoria Salgado, MD ${ }^{7}$, Ameena Ahmed, MD ${ }^{4}$, \\ and Andrew J. Karter, $P h D^{4}$
}

'Department of Medicine, University of California, San Francisco, CA, USA; ${ }^{2}$ UCSF Center for Vulnerable Populations, San Francisco General Hospital, San Francisco, CA, USA; ${ }^{3}$ California Diabetes Program, California Department of Public Health, San Francisco, CA, USA; ${ }^{4}$ Division of Research, Kaiser Permanente, Oakland, CA, USA; ${ }^{5}$ Department of Psychiatry, University of California, Oakland, CA, USA; ${ }^{6}$ UCSF, San Francisco, CA, USA.

BACKGROUND: A significant proportion of US Latinos with diabetes have limited English proficiency (LEP). Whether language barriers in health care contribute to poor glycemic control is unknown.

OBJECTIVE: To assess the association between limited English proficiency (LEP) and glycemic control and whether this association is modified by having a language-concordant physician.

DESIGN: Cross-sectional, observational study using data from the 2005-2006 Diabetes Study of Northern California (DISTANCE). Patients received care in a managed care setting with interpreter services and self-reported their English language ability and the Spanish language ability of their physician. Outcome was poor glycemic control (glycosylated hemoglobin Alc >9\%).

KEY RESULTS: The unadjusted percentage of patients with poor glycemic control was similar among Latino patients with LEP (n=510) and Latino English-speakers $(n=2,683)$, and higher in both groups than in whites $(\mathrm{n}=3,545) \quad(21 \%$ vs $18 \%$ vs. $10 \%, \mathrm{p}<0.005)$. This relationship differed significantly by patient-provider language concordance ( $\mathrm{p}<0.01$ for interaction). LEP patients with language-discordant physicians $(n=115)$ were more likely than LEP patients with languageconcordant physicians $(n=137)$ to have poor glycemic control (27.8\% vs $16.1 \% \mathrm{p}=0.02)$. After controlling for potential demographic and clinical confounders, LEP Latinos with language-concordant physicians had sim-

Study results were presented at the Society of General Internal Medicine national meeting (2009) and at the University of California, San Francisco Disparities Research Symposium (2009).

Dr. Karter had full access to all of the data in the study and takes responsibility for the integrity of the data and the accuracy of the data analysis.

Received March 5, 2010

Revised August 2, 2010

Accepted August 6, 2010

Published online September 29, 2010 ilar odds of poor glycemic control as Latino English speakers (OR 0.89; CI 0.53-1.49), whereas LEP Latinos with language-discordant physicians had greater odds of poor control than Latino English speakers (OR 1.76; CI 1.04-2.97). Among LEP Latinos, having a language discordant physician was associated with significantly poorer glycemic control (OR 1.98; CI 1.03-3.80).

CONCLUSIONS: Language barriers contribute to health disparities among Latinos with diabetes. Limited English proficiency is an independent predictor for poor glycemic control among insured US Latinos with diabetes, an association not observed when care is provided by language-concordant physicians. Future research should determine if strategies to increase language-concordant care improve glycemic control among US Latinos with LEP.

KEY WORDS: Latino/Hispanic; language; diabetes; limited English proficiency; health disparities; health communication.

J Gen Intern Med 26(2):170-6

DOI: $10.1007 / \mathrm{s} 11606-010-1507-6$

(C) The Author(s) 2010. This article is published with open access at Springerlink.com

\section{INTRODUCTION}

Population-based studies in the United States report that Latinos are disproportionately affected by diabetes, tend to have worse glycemic control, and suffer more diabetes-related complications than their white, non-Latino counterparts. ${ }^{1-4}$ Recent studies suggest that disparities in glycemic control between whites and Latinos may be increasing. ${ }^{5,6}$

Many social factors contribute to poor glycemic control among Latinos. Compared to other major population groups in the US, Latinos are the most likely to be uninsured ${ }^{7}$ and are more likely to report financial barriers to medication use. ${ }^{8}$ Latinos are also more likely than other groups to report limited English proficiency (LEP), and the proportion of Latinos with LEP 
has increased in recent years: 39\% of Latinos in the US reported speaking English less than "very well" in $2004 .^{9}$ While research involving diverse populations with diabetes has shown robust relationships between patient-physician communication, patient satisfaction, and health-promoting behaviors, ${ }^{10-12}$ it remains unclear whether language barriers render health care less effective for Latinos with diabetes and LEP or contribute to known disparities in care. The few studies that have directly examined the association between patient language and glycemic control have each concluded that language barriers are not associated with glycemic control, although these study findings may have been limited by small sample size ${ }^{13}$ or lack of detailed clinical and demographic data, ${ }^{1,14}$ or influenced by a high degree of physician-patient language concordance. ${ }^{1,15}$

We employed data from a well-characterized cohort of insured patients with diabetes to determine (1) whether LEP was associated with poor glycemic control among Latinos and (2) whether having a language-concordant physician was associated with better glycemic control among Latinos with LEP.

\section{METHODS}

The Diabetes Study of Northern California (DISTANCE) surveyed a race-stratified random sample of members of the Kaiser Permanente Northern California (KPNC) Diabetes Registry. ${ }^{16}$ The DISTANCE survey assessed a range of social, behavioral, and care-related factors that might influence diabetes outcomes. Surveys were offered in five languages (including English and Spanish) and could be completed via mail, on the web, or by phone. The survey was in the field during 2005-2006 and had a response rate of $62 \% .^{16}$

DISTANCE was approved by the institutional review boards of the Kaiser Foundation Research Institute and the University of California, San Francisco School of Medicine.

\section{Study Setting}

KPNC is a nonprofit, integrated health care delivery system providing comprehensive medical care to a diverse population of approximately 3.2 million members in Northern California. Distribution of patient demographic and socioeconomic factors is similar to that of the area population, except in the extremes of the income distribution. ${ }^{17}$ Each KPNC facility provides bilingual clinicians and interpreter services offered through qualified bilingual staff, telephone language interpreters, and on-site professional interpreters for their patients with LEP.

\section{Study Participants}

Among the $\sim 20,000$ DISTANCE respondents, there were 8,397 whose primary race/ethnic self-identification was Latino $(3,877)$ or white $(4,520)$. We excluded subjects who had an enrollment gap in the health plan of greater than 30 days in the year prior to the survey $(n=167)$, did not have at least one glycosylated hemoglobin Alc (A1c) measure in the year prior to the survey $(n=929)$, or were identified as having type 1 diabetes $(n=384)$. We also excluded those who did not respond to the survey question regarding their own English language proficiency $(n=42)$ and, among whites, excluded those report- ing difficulty with English $(\mathrm{n}=47)$. For modeling purposes, those without an assigned primary care physician (PCP) or medical care facility were excluded $(n=88)$, leaving 6,738 respondents who formed the basis for the following analysis.

\section{Study Measures}

English proficiency was assessed by asking, "How often do you have difficulty understanding or speaking English?" Those who responded "usually" or "often" were considered to have LEP, while those who responded "sometimes," "rarely," or "never" were designated as English-speaking. This item was modeled after the item used by the US Census and in other studies of LEP patients. ${ }^{18,19}$ Physician language concordance was assessed by asking the participants, "Without using an interpreter, how well does your personal physician speak your language?" LEP participants who responded "well," "very well," or "excellent" were considered to have a language-concordant primary care physician (LEP-concordant), whereas those who responded "fair," "poorly," or "does not speak my language" were considered to have a language-discordant physician (LEP-discordant). LEP patients who did not respond to the question on physician language proficiency were designated as "LEP-missing."

Demographic information and time since diabetes diagnosis were determined from patient survey responses. KPNC data from 2005 were used to generate individual comorbidity scores using the DXCG, a validated risk assessment tool designed to quantify a patient's illness burden. ${ }^{20}$ Patients whose benefit records showed no gap of greater than 30 days in pharmacy coverage during the year prior to the survey response date were categorized as having continuous pharmacy benefits.

\section{Outcome Measures}

We used the last Alc test obtained in the year prior to completion of the questionnaire to create our main outcome measure. This laboratory result was obtained during routine clinical care. Following national guidelines, we defined poor glycemic control to be Alc $>9 \% .^{21}$

\section{Statistical Analysis}

We compared characteristics of white, Latino-English-speakers and Latino patients with LEP using chi-squared tests for categorical variables and Student's t-tests for continuous variables. Among Latino patients with LEP, we compared the LEPdiscordant and the LEP-missing groups to the LEP-concordant group. We then compared the odds of poor glycemic control (Alc $>9 \%$ ) between white, Latino English-speakers and Latino patients with LEP using generalized estimating equations (GEE) models to account for clustering of patients by physician and healthcare facility. We also specified models that included an interaction term for patient-provider language concordance $\times$ LEP status to evaluate whether the LEP-Alc relationship differed by patient-provider concordance. Finding this interaction to be significant ( $\mathrm{p}<0.01$ for interaction term), we ran subsequent adjusted analyses stratified by patient-provider language concordance and LEP status. The following groups of covariates were added sequentially to adjusted models: demo- 
graphic variables (age, sex); SES (income, education); clinical characteristics (diabetes duration and co-morbidity index); and pharmacy benefits. If an individual term did not substantively alter the point estimate of the main effect, it was not considered confounding and was eliminated from the final model. We included missing indicators for all variables that were incomplete in all our models. We repeated all analyses with mean Alc as the outcome using linear GEE models. Finally, we used the Least Square Means option in SAS (SAS 9.1) to generate predicted probabilities of poor control and mean Alc by exposure group.

In order to determine if our results were sensitive to our definition of LEP, we repeated our analyses including patients who reported "sometimes" having difficulty with English in the LEP group.

\section{RESULTS}

The study population of 6,738 included 3,545 white patients, 2,683 English-speaking Latino patients, and 510 Latino patients with LEP. Patients were seen at 48 facilities, with no single facility contributing more than $10 \%$ of patients with LEP. Latino patients were cared for by 988 PCPs, of whom 296 had at least 1 study patient with LEP. The majority (90\%) of the patients with LEP were cared for by a physician who had 3 or fewer study LEP patients (range 1-13).

White, Latino English-speakers, and Latino patients with LEP differed in several ways (Table 1). Whites were more likely than either of the Latino groups to be male and report more education and greater income. English-speaking Latino patients were more likely than their LEP counterparts to be male $(50.1 \%$ vs $36.1 \%)$, have finished high school $(69.5 \%$ vs $29.0 \%)$, have annual incomes of $\$ 35,000$ or above $(56.1 \%$ vs 23.3\%), and have continuous pharmacy benefits during the year prior to the survey (94.4\% vs $85.9 \%$ ) (P value for all comparisons $<0.001$ ). Mean co-morbidity index values were similar in the two Latino groups and slightly lower than the white group.

Characteristics of the 510 patients within the three LEP groups differed only slightly. LEP-discordant patients $(n=115)$ were marginally less likely than LEP-concordant patients ( $\mathrm{n}=$ $137)$ to report an annual income under $\$ 35,000(58.3 \%$ vs $64.2 \%, \mathrm{p}=0.08$ ) and marginally more likely to have continuous pharmacy benefits $(90.4 \%$ vs $82.5 \%, p=0.07)$. LEP-missing were less likely than LEP-concordant participants to provide income information ( $8.8 \%$ vs $24.0 \%, \mathrm{p}<0.05)$.

Overall, the unadjusted percentage of patients with poor glycemic control was similar among Latino patients with LEP and Latino English-speakers and higher in both groups than in whites ( $21 \%$ vs $18 \%$ vs $10 \%$, respectively, $\mathrm{p}<0.05$ for each white vs Latino comparison); mean Alc had a similar pattern (7.8 vs 7.6 vs $7.2, \mathrm{p}<0.05$ ) (Table 1 ). However, LEP-discordant patients were more likely than LEP-concordant patients to have poor glycemic control $(27.8 \%$ vs $16.1 \%, \mathrm{p}=0.02)$ and to have somewhat higher mean Alc values (8.0 vs 7.6, $\mathrm{p}=0.07$ ).

Accounting for clustering by physician and care facility changed the univariate patterns somewhat; LEP Latino patients were more likely to be in poor glycemic control (Alc $>9 \%$ ) than English-speaking Latinos (OR 1.24; CI 1.01-1.52) (Table 2). In stratified models, LEP-concordant patients were no more likely than Latino English-speakers to have poor control (OR 0.87; 95\% CI 0.53-1.43). In contrast, LEP-discordant patients were significantly more likely to be in poor control than Latino English-speakers (OR 1.76; 95\% CI 1.06-2.93). LEPmissing had odds of poor control intermediate between those of the other two LEP groups (OR 1.23; 95\% CI 0.89-1.71).

Adjustment for covariates made minimal difference in the odds of poor control when comparing whites to Latino English speakers (OR 1.67; CI 1.44-1.95) or when comparing LEP groups to Latino English-speakers (Table 2). Final model covariates included age, sex, co-morbidity index score, time since diabetes diagnosis, and pharmacy benefits. Income and education had no significant impact on point estimates, so

Table 1. Characteristics of 6,738 Insured Patients with Diabetes by Ethnicity, English Language Proficiency, and Physician Language Concordance

\begin{tabular}{|c|c|c|c|c|c|c|}
\hline & $\begin{array}{l}\text { Whites } \\
(n=3,545)\end{array}$ & $\begin{array}{l}\text { English Latinos } \\
(n=2,683)\end{array}$ & $\begin{array}{l}\text { LEP Latinos } \\
(n=510)\end{array}$ & $\begin{array}{l}\text { LEP-Concordant PCP } \\
(n=137)\end{array}$ & $\begin{array}{l}\text { LEP-Discordant PCP } \\
(n=115)\end{array}$ & $\begin{array}{l}\text { LEP-Missing } \\
(n=258)\end{array}$ \\
\hline Age, mean (SD) & $60.6(9.4)$ & $57.3(10.8)^{\mathrm{a}}$ & $56.9(10.8)$ & $57.5(11.5)$ & $56.0(10.5)$ & $56.9(10.5)$ \\
\hline Men, n (\%) & $1,987(56.1)$ & $1,345(50.1)^{\mathrm{a}}$ & $184(36.1)^{\mathrm{b}}$ & $52(38.0)$ & $38(33.0)$ & $94(36.4)$ \\
\hline \multicolumn{7}{|l|}{ Education, n (\%) } \\
\hline Less than high school & $390(11.0)$ & $741(27.6)^{\mathrm{a}}$ & $356(69.8)^{\mathrm{b}}$ & $100(73.0)$ & $81(70.4)$ & $175(67.8)^{\mathrm{d}}$ \\
\hline High school or above & $3,121(88.0)$ & $1,864(69.5)$ & $148(29.0)$ & $33(24.1)$ & $32(27.8)$ & $83(32.1)$ \\
\hline Missing & $34(1.0)$ & $78(2.9)$ & $6(1.2)$ & $4(2.9)$ & $2(1.7)$ & 0 \\
\hline \multicolumn{7}{|l|}{ Annual household income, n (\%) } \\
\hline $0-\$ 34,999$ & $831(23.4)$ & $898(33.5)^{\mathrm{a}}$ & $296(58.0)^{\mathrm{b}}$ & $88(64.2)$ & $67(58.3)$ & $141(54.7)^{\mathrm{d}}$ \\
\hline$\geq \$ 35,000$ & $2,336(65.9)$ & $1,505(56.1)$ & 119 (23.3) & $37(27.0)$ & 27 (23.5) & $55(21.3)$ \\
\hline Missing & $378(10.7)$ & $280(10.4)$ & $95(18.6)$ & $12(8.8)$ & $21(18.3)$ & $62(24.0)$ \\
\hline Years since DM diagnosis, mean (SD) & $8.9(8.0)$ & $9.5(8.2)^{\mathrm{a}}$ & $9.5(8.5)$ & $9.8(8.3)$ & $10.1(10.1)$ & $9.1(7.9)$ \\
\hline Comorbidity score, mean (SD) & $4.76(4.9)$ & $4.4(4.7)^{\mathrm{a}}$ & $4.0(4.2)$ & $3.7(3.4)$ & $4.3(5.2)$ & $4.0(4.2)$ \\
\hline Continuous pharmacy benefits, n (\%) & $3,477(98.1)$ & $2,533(94.4)^{\mathrm{a}}$ & $438(85.9)^{b}$ & $113(82.5)$ & $104(90.4)$ & $221(85.7)$ \\
\hline HbAlc $>9 \%$, n (\%) & $353(10.0)$ & $484(18.0)^{\mathrm{a}}$ & $109(21.4)$ & $22(16.1)$ & $32(27.8)^{\mathrm{c}}$ & $55(21.3)$ \\
\hline HbAlc, mean (SD) & $7.2(1.4)$ & $7.6(1.7)^{\mathrm{a}}$ & $7.8(1.8)$ & $7.6(1.6)$ & $8.0(1.9)$ & $7.9(1.9)$ \\
\hline
\end{tabular}

Abbreviations: English Latinos: English-speaking Latinos; LEP: limited English proficient; LEP with language-concordant PCP; LEP with languagediscordant PCP; LEP-Missing: LEP without physician language data

${ }^{a}$ Whites vs. English-speaking Latinos: $p$ value $<0.05$

${ }^{b}$ English-speaking Latinos vs. LEP Latinos: $p$ value $<0.05$

${ }^{c}$ LEP-Concordant vs. LEP-Discordant: $p$ value $<0.05$

${ }^{d}$ LEP-Missing vs. LEP-Concordant: $p$ value $<0.05$

Totals may not add to $100 \%$ due to rounding 
Table 2. Association of Ethnicity, English Proficiency, and Physician Language Concordance with Poor Glycemic Control (Alc >9\%) Among Insured Patients with Diabetes in GEE Models Accounting for Clustering by Physician and Health Facility

\begin{tabular}{|c|c|c|c|c|}
\hline & & Odds ratio $(95 \% \mathrm{Cl})$ & $p$ value & LS means predicted probabilities $(95 \% \mathrm{Cl})$ \\
\hline \multirow[t]{12}{*}{ Unadjusted } & Whites & 1.00 & \multirow[t]{2}{*}{$<0.001$} & $9.81(8.7-11.1)$ \\
\hline & English Latinos & $2.00(1.72-2.33)$ & & $17.9(16.3-19.5)$ \\
\hline & English Latinos & 1.00 & \multirow[t]{2}{*}{0.04} & $17.8(16.2-19.4)$ \\
\hline & LEP Latinos & $1.24(1.01-1.52)$ & & $21.1(17.9-24.7)$ \\
\hline & English Latinos & 1.00 & \multirow[t]{2}{*}{0.58} & $17.9(16.4-19.6)$ \\
\hline & LEP-Concordant & $0.87(0.53-1.43)$ & & $15.9(10.5-23.4)$ \\
\hline & English Latinos & 1.00 & \multirow[t]{2}{*}{0.03} & $17.8(16.3-19.5)$ \\
\hline & LEP-Discordant & $1.76(1.06-2.93)$ & & $27.7(18.5-39.1)$ \\
\hline & English Latinos & 1.00 & \multirow[t]{2}{*}{0.21} & $17.9(16.4-19.5)$ \\
\hline & LEP-Missing & $1.23(0.89-1.71)$ & & $21.2(16.3-27.1)$ \\
\hline & LEP-Concordant & 1.00 & \multirow[t]{2}{*}{0.003} & 12.7 (8.6-18.4) \\
\hline & LEP-Discordant & $2.21(1.30-3.76)$ & & $24.4(16.9-33.9)$ \\
\hline \multirow[t]{8}{*}{ Adjusted $^{\mathrm{a}}$} & English Latinos & 1.00 & \multirow[t]{2}{*}{0.66} & $16.4(14.8-18.1)$ \\
\hline & LEP-Concordant & $0.89(0.53-1.49)$ & & $14.9(9.5-22.5)$ \\
\hline & English Latinos & 1.00 & \multirow[t]{2}{*}{0.03} & $16.4(14.9-18.2)$ \\
\hline & LEP-Discordant & $1.76(1.04-2.97)$ & & $25.7(16.8-37.2)$ \\
\hline & English Latinos & 1.00 & \multirow[t]{2}{*}{0.13} & $16.4(14.9-18.1)$ \\
\hline & LEP-Missing & $1.29(0.93-1.78)$ & & $20.2(15.4-26.0)$ \\
\hline & LEP-Concordant & 1.00 & \multirow[t]{2}{*}{0.04} & $11.8(7.3-18.4)$ \\
\hline & LEP-Discordant & $1.98(1.03-3.80)$ & & $20.9(13.0-31.9)$ \\
\hline
\end{tabular}

Abbreviations: English Latinos: English-speaking Latinos; LEP: limited English proficient; LEP-concordant: LEP with language-concordant physician; LEPDiscordant: LEP with language-discordant physician; LEP-Missing: LEP missing physician language data; LS Means: least squares means

aAdjusted for age, sex, comorbidity index, time since diabetes diagnosis, and continuous pharmacy benefits

these terms were not included in the final model. Direct comparison between the LEP groups revealed that LEPdiscordant patients had two-fold greater odds of poor glycemic control compared to LEP-concordant patients (OR 1.98; CI 1.03-3.80). After setting demographic and clinical covariates to the study population mean for each group, the predicted probability of poor glycemic control among LEP-discordant patients was $20.9 \%$ (CI: $13.0,31.9$ ) compared to $11.8 \%$ (CI: 7.3 , 18.4) among LEP-concordant patients.

Analysis of the association of Latino patient English proficiency and physician language concordance with Alc as a continuous outcome in GEE linear models yielded similar relationships. The LEP-concordance interaction term was significant $(p=0.03)$, and adjusted models comparing the least mean squares Alc between English-speaking and LEP-concordant groups showed no significant difference (7.64 vs $7.58, \mathrm{p}=$ 0.72). Differences in mean Alc between English-speaking and LEP-discordant groups did not reach statistical significance in adjusted models (7.64 vs $7.94, \mathrm{p}=0.18)$. In a sensitivity analysis including patients who reported "sometimes" having trouble speaking English within the LEP group, the results of the final models were qualitatively similar but with broader, non-significant confidence intervals (data not shown). Repeating all analyses using logistic regression without accounting for clustering yielded nearly identical results (data not shown).

\section{DISCUSSION}

In a study of patients with diabetes in a managed care setting with interpreter services, we found that Latino patients with limited English proficiency were somewhat more likely than English-speaking Latinos to have poor glycemic control (Alc> 9.0\%). However, the association between LEP and glycemic control was strongly modified by physician-patient language concordance. LEP patients with language-concordant physicians were no more likely to have poor glycemic control than Latino English-speaking patients; in contrast, LEP patients with language-discordant physicians were significantly more likely to have poor glycemic control. These findings were only slightly attenuated by adjustment for a selected set of demographic and clinical confounders and did not change after accounting for within-physician and within-facility clustering.

Poor glycemic control is a primary driver of diabetesassociated microvascular disease. ${ }^{22}$ The $11 \%$ absolute difference in the proportion of patients with poor glycemic control between LEP-discordant and LEP-concordant patients that we report is clinically meaningful and concerning. The $6 \%$ absolute difference in poor glycemic control between English-speaking Latinos and whites, while smaller, and not a novel finding, ${ }^{23,24}$ is also concerning and underscores the need to improve glycemic control among Latinos irrespective of English language ability.

Language barriers in health care have been associated with decreased patient satisfaction with care, increased problems with medication comprehension ${ }^{19}$, and decreased receipt of health services, even in insured patient populations. ${ }^{25,26}$ Access to professional interpreters can improve these outcomes; ${ }^{27-30}$ however, emerging evidence suggests that interpreters may be underutilized even when available, with physicians opting to use their own limited second language skills or family members as interpreters. ${ }^{31-34}$ While interpreters are available at study clinical sites, we have no measures of their use. 
Several studies have demonstrated that language-concordant care yields better outcomes. ${ }^{18,26,29,35,36}$ While the mechanism of the observed association between language concordance and improved glycemic control remains to be elucidated, it is reasonable to hypothesize that languageconcordant physicians, compared to physicians dependent on interpreters, may be better able to elicit patient concerns, ${ }^{37,38}$ explain diabetes self-management, ${ }^{19}$ persuade patients to use insulin, ${ }^{39}$ or recognize and treat the depression common among patients with diabetes. ${ }^{40}$ Physicians using interpreters have reported difficulties eliciting symptoms, explaining treatments, and eliciting treatment preferences. ${ }^{38}$ A recent DISTANCE study using data from Asian as well as Latino patients with LEP found that reports of communication competence and trust in their physician were higher when the physician was language concordant. ${ }^{41}$

Our results should be contrasted with a recent, large study of patients with diabetes cared for in managed care settings that reported no difference in glycemic control by the preferred language of Latino patients. ${ }^{42}$ In that study, the majority of Spanish-speaking patients were cared for by Spanish-speaking physicians. Our finding of no differences in glycemic control between LEP-concordant vs English-speaking Latino patients is consistent with the previous study's lack of difference given their high prevalence of language-concordant physicians. Our use of poor glycemic control as our main outcome measure also differs from other studies. Poor glycemic control may be a more clinically relevant and sensitive outcome than mean glycemic control. ${ }^{43}$

The study has several limitations. First, while our results may not be generalizable to the very poor or very wealthy, we found that income and education did not impact our models; however, differences between Latinos and whites may be conservative in so far as Latinos within Kaiser generally do not have medication and health care access barriers to glycemic control. Second, while survey participants may differ from non-respondents, we found few differences based on clinical data and census-based socioeconomic data, which were available for all members of the cohort. ${ }^{16}$ Third, most Latinos in the DISTANCE registry are of Mexican ancestry; the association between LEP and poor glycemic control may be different among Latinos of other nationalities. ${ }^{44,45}$ Fourth, we are unable to distinguish language barriers from cultural barriers to care. Fifth, we used patient report of physician language fluency to determine concordance and have no independent measure of physician fluency or use of interpreter services. Sixth, LEP patients with language-concordant physicians may differ from those with discordant physicians in ways our data do not capture, and these unmeasured differences may contribute to the observed differences in glycemic control. Seventh, while we used a single measure of glycemic control, studies suggest that a single glycemic value can predict microsvascular events ${ }^{46}$ and that exposure to poor control can impart a lasting "legacy effect" on microvascular and macrovascular events years after glycemic control equalizes between groups. ${ }^{47}$

This study also has several strengths. We examined glycemic control for Latino patients with uniform access to prepaid health care, and the associations we observe among patient language, physician language concordance, and glycemic control are not confounded by differences in health care coverage. In addition, KPNC study sites comply with federal language access services statutes and offer high-quality interpreter services to their patients. Among health plans in California, Kaiser Permanente has the lowest rate of patientreported problems with access and quality of care for patients with LEP. ${ }^{48}$ Differences in glycemic control between languageconcordant and language-discordant interactions may be even greater at health care facilities with more limited availability of interpreter services. Finally, we had access to patient selfreport of English language proficiency, the current standard in determining LEP status. ${ }^{49}$

Our study has several implications. First, it confirms that without assurance of language-concordant providers, LEP should be considered a risk factor for less effective health care, even in a context of access to qualified interpreters. Currently, most quality improvement efforts do not place language on par with race, ethnicity, or socioeconomic data. This study and others suggest that LEP status should be included in quality reporting, as important heterogeneity in Latino populations is obscured when only ethnicity is examined. ${ }^{48}$ Second, our study suggests that language-concordant care may make it easier to navigate the myriad issues thought to influence ethnic disparities in glycemic control generally, ${ }^{50}$ and glycemic control among Latinos patients with LEP more specifically, including cultural attitudes toward diabetes, ${ }^{51}$ diabetes medications, ${ }^{52,53}$ prevention, ${ }^{54}$ and diet, ${ }^{5,56}$ as well as acculturation, ${ }^{57}$ limited health literacy, ${ }^{58}$ and high rates of depression. ${ }^{59}$ While this observational study cannot provide evidence for causality, health plans should consider systematically offering the choice of language-concordant primary care physicians to patients with diabetes and LEP. The widespread distribution of patients with LEP throughout the country already renders increasing the linguistic capacity of the current physician workforce a priority. ${ }^{31,60}$

\section{CONCLUSION}

In the 2000 census, $8.1 \%$ of the US population, 18 million adults, most of them Latinos, reported speaking English less than very well. ${ }^{61}$ Latinos with LEP currently constitute nearly half of the California Latino population with diabetes. ${ }^{62}$ Patients with LEP and diabetes-an illness that demands substantial knowledge, self-management, and ongoing interaction with the medical system-may be particularly vulnerable to the challenges posed by inadequate communication. Our study finds that LEP is a contributor to ethnic disparities and a significant and independent predictor of poor glycemic control among Latinos with diabetes, an association not observed when care is provided by language-concordant physicians. Future research should determine if strategies to link Spanishspeaking patients with Spanish-speaking physicians reduce language and ethnic disparities in glycemic control.

Acknowledgments: We thank Joe Selby, MD, for critical review of a draft of this manuscript.

Funding: Dr. Fernandez was supported by an NIH Career Development Award (K23-RR018324-01) and by a professorship award from the Arnold P. Gold Foundation. Dr. Schillinger was supported by an NIH Clinical and Translational Science Award UL1 
RR024131. Dr. Schenker was supported by the General Internal Medicine Fellowship at UCSF, funded by the Department of Health and Human Services, Health Resources and Services Administration (DHHS HRSA D55HP05165). Dr. Karter, Warton MPH, Moffet $M P H$, and Dr. Ahmed were supported by National Institute of Diabetes and Digestive and Kidney Diseases RO1 DK065664 National Institute of Child and Human Development (RO1 HD046113) RO1 HD046113. Funders had no role in any aspect of the study.

\section{Conflict of Interest: None disclosed.}

Open Access: This article is distributed under the terms of the Creative Commons Attribution Noncommercial License which permits any noncommercial use, distribution, and reproduction in any medium, provided the original author(s) and source are credited.

Corresponding Author: Alicia Fernandez, MD; UCSF, Box 1364, San Francisco, CA 94143, USA (e-mail: afernandez@medsfgh.ucsf. edu).

\section{REFERENCES}

1. Lasater LM, Davidson AJ, Steiner JF, Mehler PS. Glycemic control in English- vs Spanish-speaking Hispanic patients with type 2 diabetes mellitus. Arch Intern Med. 2001;161(1):77-82.

2. Mainous Iii AG, Diaz VA, Koopman RJ, Everett CJ. Quality of care for Hispanic adults with diabetes. Fam Med. 2007;39(5):351-356.

3. Harris MI. Racial and ethnic differences in health care access and health outcomes for adults with type 2 diabetes. Diab Care. 2001;24(3):454-459.

4. CDC. Health disparities experienced by hispanics-United States 2004.

5. McWilliams JM, Meara E, Zaslavsky AM, Ayanian JZ. Differences in control of cardiovascular disease and diabetes by race, ethnicity, and education: US trends from 1999 to 2006 and effects of Medicare coverage. Ann Intern Med. 2009;150(8):505-515.

6. Hoerger TJ, Segel JE, Gregg EW, Saaddine JB. Is glycemic control improving in US adults? Diab Care. 2008;31(1):81-86.

7. DeNavas-Walt C, Proctor BD, Smith JC. Current population reports: Income, poverty and health insurance coverage in the United States: 2007. Washington, DC 2008.

8. Tseng CW, Tierney EF, Gerzoff RB, et al. Race/ethnicity and economic differences in cost-related medication underuse among insured adults with diabetes: the Translating Research Into Action for Diabetes Study. Diab Care. 2008;31(2):261-266.

9. US Census Bureau. The American Community-Hispanics: 2004. 2007.

10. Schillinger D, Piette J, Grumbach $\mathbf{K}$, et al. Closing the loop: physician communication with diabetic patients who have low health literacy. Arch Intern Med. 2003;163(1):83-90.

11. Piette JD, Schillinger D, Potter MB, Heisler M. Dimensions of patientprovider communication and diabetes self-care in an ethnically diverse population. J Gen Intern Med. 2003;18(8):624-633.

12. Sequist TD, Schneider EC, Anastario M, et al. Quality monitoring of physicians: linking patients' experiences of care to clinical quality and outcomes. J Gen Intern Med. 2008;23(11):1784-1790.

13. Perez-Stable EJ, Napoles-Springer A, Miramontes JM. The effects of ethnicity and language on medical outcomes of patients with hypertension or diabetes. Med Care. 1997;35(12):1212-1219.

14. Tocher TM, Larson E. Quality of diabetes care for non-English-speaking patients. A comparative study. West J Med. 1998;168(6):504-511.

15. Brown AF, Gregg EW, Stevens MR, et al. Race, ethnicity, socioeconomic position, and quality of care for adults with diabetes enrolled in managed care: the Translating Research Into Action for Diabetes (TRIAD) study. Diab Care. 2005;28(12):2864-2870.

16. Moffet HH, Adler N, Schillinger D, et al. Cohort Profile: The diabetes study of Northern California (DISTANCE) - objectives and design of a survey follow-up study of social health disparities in a managed care population. Int $\mathrm{J}$ Epidemiol. 2008 Mar 7.

17. Karter AJ, Moffet HH, Liu J, et al. Achieving good glycemic control: initiation of new antihyperglycemic therapies in patients with type 2 diabetes from the Kaiser Permanente Northern California Diabetes Registry. Am J Manag Care. 2005;11(4):262-270.

18. Fernandez A, Schillinger D, Grumbach K, et al. Physician language ability and cultural competence. An exploratory study of communication with Spanish-speaking patients. J Gen Intern Med. 2004;19(2):167-174.

19. Wilson E, Chen AH, Grumbach K, Wang F, Fernandez A. Effects of limited English proficiency and physician language on health care comprehension. J Gen Intern Med. 2005;20(9):800-806.

20. Zhao Y, Ellis RP, Ash AS, et al. Measuring population health risks using inpatient diagnoses and outpatient pharmacy data. Health Serv Res. 2001;36(6 Pt 2):180-193.

21. Saaddine JB, Cadwell B, Gregg EW, et al. Improvements in diabetes processes of care and intermediate outcomes: United States, 1988-2002. Ann Intern Med. 2006; 144(7):465-474.

22. Stratton IM, Adler AI, Neil HA, et al. Association of glycaemia with macrovascular and microvascular complications of type 2 diabetes (UKPDS 35): prospective observational study. Bmj. 2000;321 (7258):405-412.

23. Rodondi N, Peng T, Karter AJ, et al. Therapy modifications in response to poorly controlled hypertension, dyslipidemia, and diabetes mellitus. Ann Intern Med. 2006; 144(7):475-484.

24. Winston GJ, Barr RG, Carrasquillo O, Bertoni AG, Shea S. Sex and racial/ethnic differences in cardiovascular disease risk factor treatment and control among individuals with diabetes in the Multi-Ethnic Study of Atherosclerosis (MESA). Diab Care. 2009;32(8):1467-1469.

25. Morales LS, Cunningham WE, Brown JA, Liu H, Hays RD. Are Latinos less satisfied with communication by health care providers? J Gen Intern Med. 1999;14(7):409-417.

26. Cheng EM, Chen A, Cunningham w. Primary language and receipt of recommended health care among Hispanics in the United States. J Gen Intern Med. 2007;22(Suppl 2):283-288.

27. Jacobs EA, Lauderdale DS, Meltzer D, Shorey JM, Levinson W, Thisted RA. Impact of interpreter services on delivery of health care to limited-English-proficient patients. J Gen Intern Med. 2001;16(7):468-474.

28. Karliner LS, Jacobs EA, Chen AH, Mutha S. Do professional inter preters improve clinical care for patients with limited English proficiency? A systematic review of the literature. Health Serv Res. 2007;42 (2):727-754.

29. Gany F, Leng $\mathbf{J}$, Shapiro $\mathbf{E}$, et al. Patient satisfaction with different interpreting methods: a randomized controlled trial. J Gen Intern Med. 2007;22(Suppl 2):312-318.

30. Baker DW, Hayes R, Fortier JP. Interpreter use and satisfaction with interpersonal aspects of care for Spanish-speaking patients. Med Care. 1998;36(10):1461-1470.

31. Diamond LC, Reuland DS. Describing physician language fluency: deconstructing medical Spanish. Jama. 2009;301(4):426-428.

32. Diamond LC, Schenker Y, Curry L, Bradley EH, Fernandez A. Getting by: underuse of interpreters by resident physicians. J Gen Intern Med. 2009;24(2):256-262.

33. Ferguson WJ. Un poquito. Health Aff (Millwood). 2008;27(6):1695-1700.

34. Schenker Y, Wang F, Selig SJ, Ng R, Fernandez A. The impact of language barriers on documentation of informed consent at a hospital with on-site interpreter services. J Gen Intern Med. 2007;22(Suppl 2):294-299.

35. Ngo-Metzger Q, Sorkin DH, Phillips RS, et al. Providing high-quality care for limited English proficient patients: the importance of language concordance and interpreter use. J Gen Intern Med. 2007;22(Suppl 2):324-330,

36. Green AR, Ngo-Metzger Q, Legedza AT, Massagli MP, Phillips RS, Iezzoni LI. Interpreter services, language concordance, and health care quality. Experiences of Asian Americans with limited English proficiency. J Gen Intern Med. 2005;20(11):1050-1056.

37. Rivadeneyra R, Elderkin-Thompson V, Silver RC, Waitzkin H. Patient centeredness in medical encounters requiring an interpreter. Am J Med. 2000; 108(6):470-474.

38. Karliner LS, Perez-Stable EJ, Gildengorin G. The language divide. The importance of training in the use of interpreters for outpatient practice. $J$ Gen Intern Med. 2004;19(2): 175-183.

39. Campos C. Addressing cultural barriers to the successful use of insulin in Hispanics with type 2 diabetes. South Med J. 2007;100 (8):812-820.

40. Sentell T, Shumway M, Snowden L. Access to mental health treatment by English language proficiency and race/ethnicity. J Gen Intern Med. 2007;22(Suppl 2):289-293. 
41. Schenker Y, Karter A, Schillinger D, et al. The impact of limited English proficiency and physician language concordance on reports of clinical interactions among patients with Diabetes: the DISTANCE Study. Patient Educ Couns. 2010(epub.).

42. Brown AF, Gerzoff RB, Karter AJ, et al. Health behaviors and quality of care among Latinos with diabetes in managed care. Am J Public Health. 2003;93(10): 1694-1698.

43. Aron D, Pogach L. Transparency standards for diabetes performance measures. Jama. 2009;301(2):210-212.

44. Weinick RM, Jacobs EA, Stone LC, Ortega AN, Burstin H. Hispanic healthcare disparities: challenging the myth of a monolithic Hispanic population. Med Care. 2004;42(4):313-320.

45. Mainous AG 3rd, Diaz VA, Saxena S, Geesey ME. Heterogeneity in management of diabetes mellitus among Latino ethnic subgroups in the United States. J Am Board Fam Med. 2007;20(6):598-605.

46. Bash LD, Selvin E, Steffes M, Coresh J, Astor BC. Poor glycemic control in diabetes and the risk of incident chronic kidney disease even in the absence of albuminuria and retinopathy: Atherosclerosis Risk in Communities (ARIC) Study. Arch Intern Med. 2008;168 (22):2440-2447.

47. Holman RR, Paul SK, Bethel MA, Matthews DR, Neil HA. 10-year follow-up of intensive glucose control in type 2 diabetes. N Engl J Med. 2008;359(15): 1577-1589.

48. Fernandez A, Viloria J, Wu E, Martinez M, Wang F, Selig S. The impact of race/ethnicity and language on access and experience of care among California's commercially insured adults. February 2007.

49. Baker DW, Cameron KA, Feinglass J, et al. A system for rapidly and accurately collecting patients' race and ethnicity. Am J Public Health. 2006;96(3):532-537.

50. Selby JV, Swain BE, Gerzoff RB, et al. Understanding the gap between good processes of diabetes care and poor intermediate outcomes: Translating Research into Action for Diabetes (TRIAD). Med Care. 2007;45(12): 1144-1153.
51. Caban A, Walker EA. A systematic review of research on culturally relevant issues for Hispanics with diabetes. Diabetes Educ. 2006;32 (4):584-595.

52. Hatcher E, Whittemore R. Hispanic adults' beliefs about type 2 diabetes: clinical implications. J Am Acad Nurse Pract. 2007;19 (10):536-545.

53. Huang ES, Brown SE, Thakur N, et al. Racial/ethnic differences in concerns about current and future medications among patients with type 2 diabetes. Diab Care. 2009;32(2):311-316.

54. Sullivan LV, Hicks P, Salazar G, Robinson CK. Patient beliefs and sense of control among spanish-speaking patients with diabetes in Northeast Colorado. J Immigr Minor Health. 2009 Mar 6.

55. Mainous AG 3rd, Diaz VA, Geesey ME. Acculturation and healthy lifestyle among Latinos with diabetes. Ann Fam Med. 2008;6(2):131-137.

56. Gordon NP, Iribarren C. Health-related characteristics and preferred methods of receiving health education according to dominant language among Latinos aged 25 to 64 in a large Northern California health plan. BMC Public Health. 2008;8:305.

57. Mainous AG 3rd, Majeed A, Koopman RJ, et al. Acculturation and diabetes among Hispanics: evidence from the 1999-2002 National Health and Nutrition Examination Survey. Public Health Rep. 2006;121(1):60-66.

58. Schillinger D, Grumbach K, Piette J, et al. Association of health literacy with diabetes outcomes. Jama. 2002;288(4):475-482.

59. Gross R, Olfson M, Gameroff MJ, et al. Depression and glycemic control in Hispanic primary care patients with diabetes. J Gen Intern Med. 2005;20(5):460-466.

60. Schenker Y, Lo B, Ettinger KM, Fernandez A. Navigating language barriers under difficult circumstances. Ann Intern Med. 2008;149 (4):264-269.

61. U.S. Census Bureau. Census 2000, Summary File 3. Accessed July 10, 2009

62. California Health Interview Survey. www.chis.ucla.edu. UCLA Center for Health Policy \Accessed July 2009. 